Pak. j. sci. ind. res. Ser. B: biol. sci. 2021 64B(3) 211-216

\title{
Effect of Endectocides and Antibiotic Dung Poisoning on Mortality of Dung Beetle Species
}

\author{
Mubashar Hussain*, Mobeen Ghazanfar, Muhammad Faheem Malik, \\ Muhammad Umar and Misbah Younas \\ Department of Zoology, Faculty of Science, University of Gujrat, Punjab, Pakistan
}

(received June 14, 2018; revised April 12, 2019; accepted April 19, 2020)

\begin{abstract}
We explored the effect of endectocides (deltamethrin and trichlorophenol) and antibiotics (enrofloxacin and oxytetracycline) on dung beetle species, Onthophagus gazella and Onitis excavatus under laboratory conditions. O. gazella and $O$. excavatus were collected from pastures and crop lands of Jhelum, Punjab, Pakistan. The selected endectocides and antibiotics were applied on dung pats placed over soil @ $0.25,0.50,0.75$ and 1 ppm and kept in glass containers of $2^{\prime}$ x 2' x 1.5' size. The laboratory bioassay was carried out at $28 \pm 2{ }^{\circ} \mathrm{C}$ temperature and $65 \pm 5 \% \mathrm{RH}$ with 12:12 of light to darkness ratio. Our results demonstrated that deltamethrin, trichlorophenol and oxytetracycline were toxic to both species, O. gazella and $O$. excavatus after two weeks of the exposure. Comparatively higher dung beetle mortality was recorded in both deltamethrin and trichlorophenol when applied @1 ppm as compared to 0.25, 0.50 and 0.75 ppm concentrations in $O$. gazella and $O$. excavatus showed significantly higher mortality against oxytetracycline (53.3\% and $93.3 \%$, respectively), trichlorophenol (80\% and $94 \%$, respectively) and deltamethrin (88 $\%$ and $76 \%$, respectively) at $1 \mathrm{ppm}$ concentrations, whereas no mortality was recorded in all concentrations of enrofloxacin. O. gazella and O. excavatus responded negatively to the presence of different concentrations of veterinary parasiticides. In addition to the hazardous effect of $O$. gazella and $O$. excavatus, the study reports that these dung beetle species can be exploited as bio-indicators for environmental assessment in ecosystem studies.
\end{abstract}

Keywords: veterinary medicines, O. gazella, hazardous effect, non-target species, O. excavatus

\section{Introduction}

Endectocides treated animals excrete residue of parasiticides primarily in the feces, thus making it poisonous for dung dwelling or eating arthropod fauna, reducing insect abundance associated with the dung decomposition resulting in severe ecological and economic costs (Baena-Díaz et al., 2018). Owing to low mammalian toxicity the endectocides and veterinary parasiticides, are globally used against arthropods and nematode parasites (Floate, 2006). Environmentalists show grave concerns about the deleterious effects of endectocides on the dung-inhabiting fauna that decomposes dung (Foster et al., 2014; Floates 2006). Significant larval mortality of dung beetles occur in the brood balls of endectocides treated cattle (Iwasa and Sugitani, 2014).

Many drugs are excreted in the feces of treated animals that affect the beneficial insects involved in the decomposition of dung pats (Lumaret et al., 2012; Lumaret et al., 2005) primarily dung beetles and flies (Chihiya et al., 2015). Irrespective of the animal species

*Author for correspondence; E-mail: dr.mubashar@uog.edu.pk or method of administration most of the number of drugs applied is excreted infrangible and the insecticidal activity remains in the dung for days (Jacob and Scholtz, 2015; Iwasa et al., 2007).

Higher larval and pupal mortality, delayed development and lest allure to drug contaminated dung was observed by the coprophilous arthropods. The deleterious effects of anti-parasitic drugs result in the population decline of non-target dung dwelling species by halting basic biological happenings, thus, contributing to biodiversity loss (Suarez et al., 2003). Population index of dung beetles has a directrelationship with the intensity of the endectocides contaminated dung pats (Floate, 2006). Dung beetles represent one of the key insect environmental indicators of biodiversity loss and ecosystem instability due to anthropogenic interventions (Davis et al., 2004). Thus, there is a need for constant biological monitoring of dung beetle populations in pastures, croplands and agro-ecosystems.

The current study was conducted in vivo bioassay to determine the effect of endectocides and antibiotics on two common species of dung beetle, $O$. gazella and $O$. 
excavatus with the hypothesis that veterinary drugs affect these non-target beneficial species which could be environmental pollution indicators. Onthophagus gazella and $O$. excavatus have not been yet explored in the context of environmental indicators of antiparasitic and antibiotic drugs excreted in the feces of cattle. Our study would provide an insight to conclude the role of endectocides and antibiotics on the biodiversity of non-target species.

\section{Materials and Methods}

Study area. The study on the systematics of dung beetles species collected from pastures and croplands of Jhelum, Punjab, Pakistan was conducted in the Laboratory of Systematics and Pest Management, Department of Zoology, University of Gujrat during 2015-2016 (Fig. 1). Owing to diversity and distribution patterns of dung beetle fauna in the study area, the effect of antibiotic and anti-parasitic drugs on mortality of $O$. gazella and O. excavatus was assessed in the laboratory bioassay (Ghazanfar et al., 2017).

Experimental specimens. Adult specimens of $O$. gazella and $O$. excavatus were collected from untreated cattle dung by hand picking and homogenized method and subjected to identification in the laboratory (Ghazanfar et al., 2017).

Collection of fresh dung. Cattle dung was used to rear the beetles which were collected from dairy farms adjacent to the University of Gujrat after ensuring the non-presence or mixing of any material having a detrimental effect to the dung beetles.

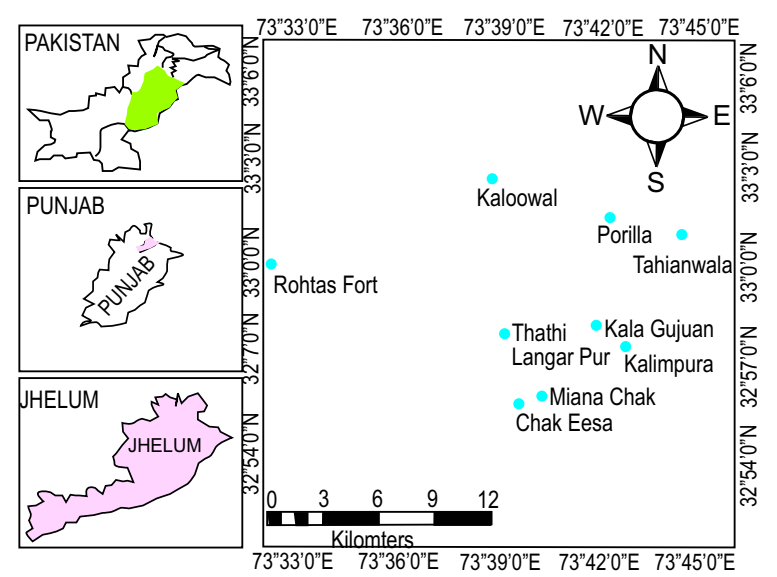

Fig. 1. Map showing of sampling sites for the collection of specimens of O.gazella and O.excavatus from Jhelum, Punjab, Pakistan.
Soil sampling. The soil samples were collected from the study sites from where beetle fauna was collected. The sample were and treated in the incubator at $70{ }^{\circ} \mathrm{C}$ for 2 days before using in the experiment to kill microbes and parasites (Boleas et al., 2005).

Preparation of different concentrations. The different concentrations $(0.25 \mathrm{ppm}, 0.5 \mathrm{ppm}, 0.75 \mathrm{ppm}$ and 1 $\mathrm{ppm}$ ) of the selected antiparasitic and antibiotics were prepared to evaluate their effect on dung beetles (Lumaret, 1986).

Laboratory bioassay procedure. Adults of $O$. gazella and $O$. excavatus were reared on dung pats treated with $0.25 \mathrm{ppm}, 0.5 \mathrm{ppm}, 0.75 \mathrm{ppm}$ and $1 \mathrm{ppm}$ of each antiparasitic drug and antibiotics were applied by using Potter Tower Sprayer. The experimental units were kept at room temperature of $28 \pm 2^{\circ} \mathrm{C}$ and $65 \pm 5 \% \mathrm{RH}$ with 12:12 of light to darkness ratio. Each experimental unit was comprised of five male and five female adult dung beetles placed in a $2^{\prime} \times 2^{\prime} \times 1.5^{\prime}$ size glass containers provided with soil collected from their natural habitat.

Data collection and analysis. The experiment was laid down in Completely Randomized Design (CRD) with 17 treatments each replicated thrice and data was collected on mortality of beetles after two weeks of the exposure. Dung beetles which were unable to move any part or segment of their body were considered as dead. Dung beetles were counted and mortality was adjusted by applying Abbott's Formula (Verdú et al., 2015). The data were subjected to statistical analysis for the comparison. $\mathrm{LC}_{50}$ and $\mathrm{LC}_{90}$ values for different drugs were calculated by using Probit Analysis (Abbott, 1925). The statistical analysis was performed by using SPSS 21.

\section{Results and Discussion}

In the laboratory bioassay, $\mathrm{LC}_{50}$ and $\mathrm{LC}_{90}$ values were calculated by applying a series of doses of different concentrations on dung pats inhabiting $O$. gazella and $O$. excavatus. The lower values of $\mathrm{LC}_{50}$ and $\mathrm{LC}_{90}$ of endectocides for the mortality of $O$. gazella and $O$. excavatus showed their greater toxicity to dung beetle species where as higher values of antibiotics suggested less toxicity against non-target O.gazella and $O$. excavatus (Table 1).

Effect of oxytetracycline on O. gazella and $O$. excavatus. The significant variations in the mortality of adult dung beetles, O.gazella and O. excavatus, were recorded after two weeks exposure to the different 
Table 1. $\mathrm{LC}_{50}$ and $\mathrm{LC}_{90}$ values of different treatments against $O$. gazella and $O$. excavatus after two weeks of application in the laboratory bioassay

\begin{tabular}{lcccc}
\hline \hline & \multicolumn{2}{c}{ O. gazella } & \multicolumn{2}{c}{ O. excavatus } \\
\hline & $\begin{array}{l}\mathrm{LC}_{50} \\
(\%)\end{array}$ & $\begin{array}{l}\mathrm{LC}_{90} \\
(\%)\end{array}$ & $\begin{array}{l}\mathrm{LC}_{50} \\
\mathbf{( \% )}\end{array}$ & $\begin{array}{l}\mathrm{LC}_{90} \\
(\%)\end{array}$ \\
\hline Antibiotic drugs & & & & \\
$\begin{array}{l}\text { Enrofloxacin } \\
\text { Oxytetracycline }\end{array}$ & 15.594 & 48.50 & 2.42 & 5.45 \\
$\begin{array}{l}\text { Antiparasitic drugs } \\
\text { Trichlorophenol }\end{array}$ & 01.120 & 3.488 & 0.50 & 1.13 \\
\begin{tabular}{l} 
Deltamethrin \\
\hline \hline
\end{tabular} & 0.23 & 0.721 & 0.21 & 0.49 \\
\hline
\end{tabular}

concentrations of oxy-tetracycline i.e. $0.25,0.50,0.75$ to $1 \mathrm{ppm}$. Increasing trend in the mortality was observed with the increase in the concentration from $0.25 \mathrm{ppm}$ to $1 \mathrm{ppm}$, whereas no mortality was recorded in the control showed significant differences $\left(\mathrm{F}_{3,95}=75.52\right.$, $\mathrm{P}<0.05)$ in the mortality of both species at different concentrations of oxy-tetracycline (Fig. 1). O. excavatus indicated significantly higher mortality $(93.3 \%)$ as compared to $O$. gazella $(53.3 \%)$ at $1 \mathrm{ppm}$. The data also showed significant differences in the mortality of both species at different concentrations of oxytetracycline (Fig.2).

Effect of trichlorophenol. The data indicated higher mortality of O.gazella and O.excavatus at all concentrations, whereas no mortality in control. Both

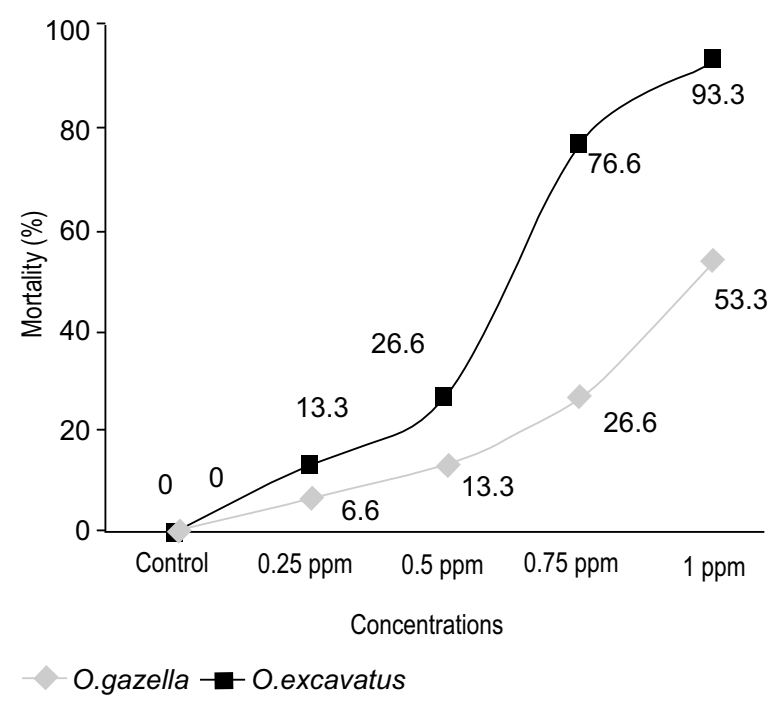

Fig. 2. Effect of oxytetracycline treated dung on the mortality of $O$. gazella and $O$. excavatus after two weeks of exposure. species showed greater mortality at 0.75 and $1 \mathrm{ppm}$ as compared to $0.25,0.5 \mathrm{ppm}$ and control. The data depicted significant differences in the mortality of two species $\left(\mathrm{F}_{1,95}=5.14, \mathrm{P}<0.05\right)$ at different concentrations (Fig. 3).

Effect of deltamethrin. The exposure of dung beetle species to different concentrations of deltamethrin resulted in the mortality of both species at all concentrations, whereas no mortality was observed in control where no treatment was applied. The higher mortality was observed at higher concentrations of deltamethrin (Fig. 4). The results showed significant differences between drugs $\left(\mathrm{F}_{3,95}=273.24, \mathrm{P}<0.05\right)$.

Effect of enrofloxacin. The results indicated no mortality when dung was treated with different concentrations of enrofloxacin.

Comparative effects of anti-parasitic drugs and antibiotics on $\boldsymbol{O}$. gazella. $O$. gazella indicated significant variations in the mortality against anti-parasitic drugs after an exposure of two weeks. Effect of different concentrations $(0.25,0.5,0.75$ and $1 \mathrm{ppm})$ in each treatment group (oxytetracycline, trichlorophenol and deltamethrin) indicated greater mortality of $O$. gazella with the increase in the concentration $(0.25$ to $1 \mathrm{ppm})$. Significant differences were observed between concentrations of endectocides and antibiotics for each treatment group $\left(\mathrm{F}_{1,95}=5.14, \mathrm{P}<0.05\right)$ where as, no mortality was recorded in control (Fig. 5).

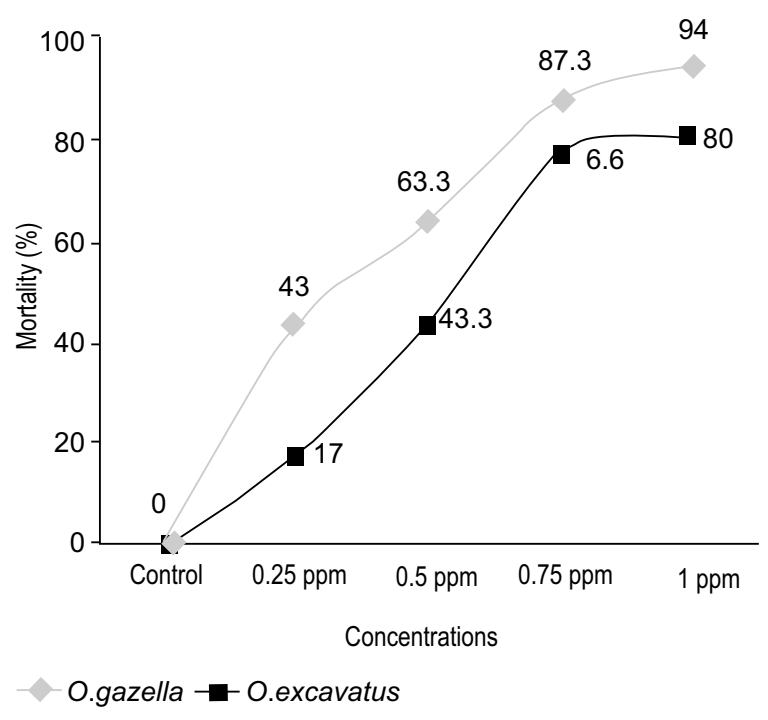

Fig. 3. Effect of trichlorophenol treated dung on the mortality of $O$. gazella and $O$. excavatus after two weeks of exposure. 


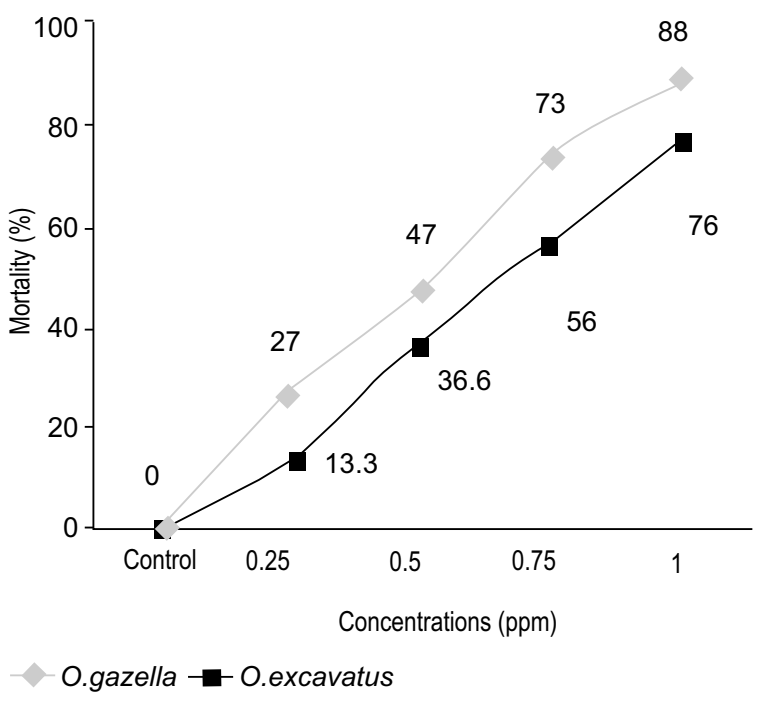

Fig. 4. Effect of deltamethrin treated dung on the mortality of $O$. gazella and O.excavatus after two weeks of exposure.

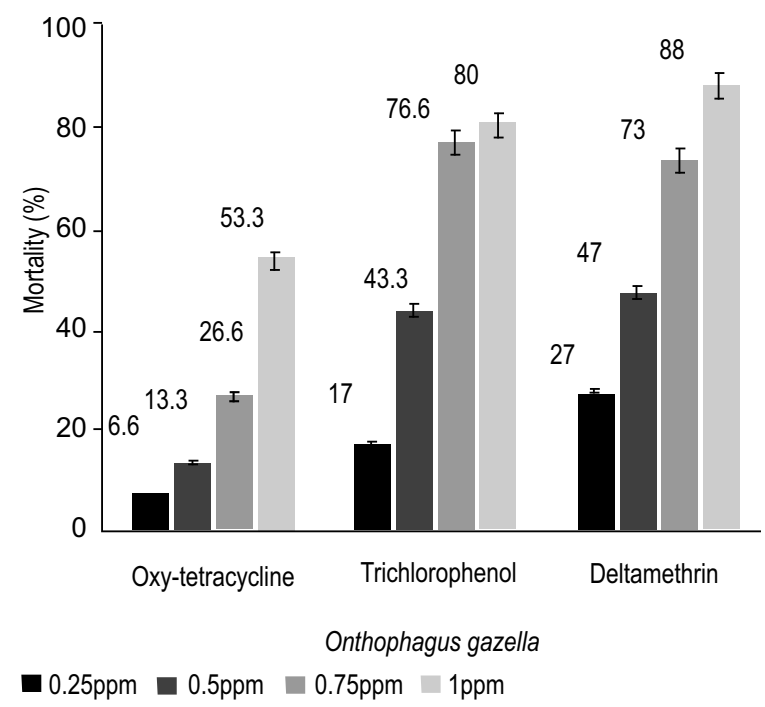

Fig. 5. Comparative effect of various concentrations of antiparasitic drugs and antibiotics on the mortality of $O$. gazella after two weeks of exposure.

Comparative effects of anti-parasitic drugs and antibiotics on $O$. excavatus. Mortality of $O$. excavatus indicated significant variations in the mortality of dung beetles against antiparasitic drugs and antibiotics. Significant differences $\left(\mathrm{F}_{1,95}=5.14, \mathrm{P}<0.05\right)$ were observed between concentrations of each treatment group i.e. oxy-tetracycline, trichlorophenol and deltamethrin (Fig. 6). The data indicated that higher

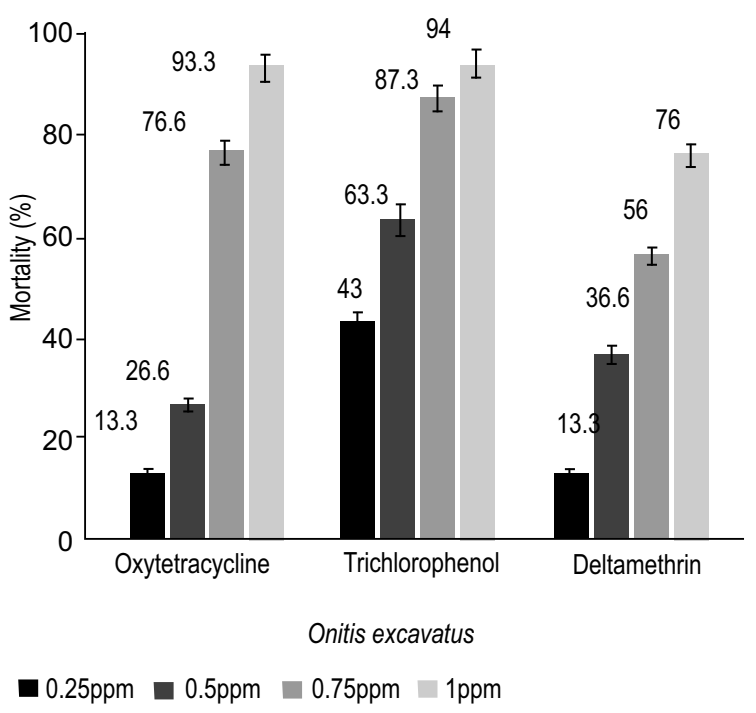

Fig. 6. Comparative effect of various concentrations of antiparasitic drugs and antibiotics on the mortality of $O$. excavatus after two weeks of exposure.

mortality was recorded at $1 \mathrm{ppm}$ concentration of all treatment groups, whereas no mortality was recorded in the control of each treatment group.

Dung beetles mortality was assessed by exposing adults of $O$. gazella and $O$. excavatus to anti-parasitic and antibiotic treated dung pats. Our results showed that both species exhibited mortality against the anti-parasitic drugs, whereas no mortality was recorded in groups exposed to Enrofloxacin treated dung pats. Earlier studies reported that the presence of hazardous material in the dung may lead to feeding non-preference, ingesting hazardous material, and change in the brooding behaviour (Blume, 1975). Ingesting anti-parasitic drugs may have led towards the greater mortality of dung beetles. The studies explored that the volatile compounds emitted by dung are utilized by the dung beetles to locate fresh sources of dung which may be masked by the presence of antibiotic and anti-parasitic drugs, thus, may result in slowing down the growth and development of dung beetles (Dormont et al., 2007; Dormont et al., 2004; Burger, 1975).

The studies on the toxicity of endectocides (Ivermectin, Eprinomectin, Methoprene and Abamectin) against dung beetles and dung flies reported adverse effects (Iwasa et al., 2007; Hooper and Wolfson, 1985). Veterinary anti-parasitic drugs have undesirable effects on dung beetle species as our study reported that drugs 
like trichlorophenol negatively influenced the dung beetles species i.e. O. gazella and $O$. excavatus. However, in our study we experienced no dung beetle mortality in case of enrofloxacin treated pats at all concentrations which coincide with the results reported by Chandra et al. (2012) who studied the acute toxic effect of enrofloxacin on the growth, reproduction and development of Eisina festidia and concluded that non target fauna like dung beetles remained unaffected by antibiotics. Our results are also similar to Li et al. (2015) who reported no mortality of dung beetles when exposed to enrofloxacin. Both species of dung beetles under consideration showed sensitivity even at the lower concentration $(0.25 \mathrm{ppm})$ of deltamethrin which is in line with Iwasa et al. (2014) who reported that Scarabaeide beetles were sensitive to $0.01 \mathrm{mg}$ per litter of deltamethrin.

The study documented that veterinary drugs have lethal and sub-lethal effects on non-target species belonging to scarabaeide beetles. Our findings are in line with those of earlier researchers who reported negative effects of such products on the scarabaeid beetles that depend on the dose, concentration, species and application method (Lumaret et al., 2012; Lumaret et al., 2005). Pest management drugs used against parasites of veterinary animals negatively affect immature and adult forms of beetles reducing their chances of survival, disturbing physiological processes lowering their capacity in the dung decomposition. The study asserts its application in the use of selected anti-parasitic drugs for livestock pest management. The study further reports that dung beetle community structure may be affected by the presence of residue of drugs administered to the livestock for parasite management, thus, lowering the ability of fauna inhibiting the dung.

\section{Conclusion}

This research work provided evidence that the population of dung beetles belonging to two representative genera Onthophagus and Onitis collected from pastures may be adversely affected by the use of veterinary drugs especially anti-parasitic drugs. The result demonstrated that the population of Onthophagus and Onitis species may be adversely affected, thus may lead to community disturbance and contribute in biodiversity loss. Trichlorophenol and deltamethrin showed highly toxic effect on $O$. gazellaand $O$. excavatus and reducing their population by about $80 \%$ when the concentration of treated pats was higher. The descending order of mortality observed in this work was trichlorophenol $>$ deltamethrin $>$ oxytetracycline $>$ enrofloxacin. The judicious use of these drugs in addition to sanitary measures may help in preventing biodiversity loss, better nutrient recycling and improving the decomposition rates.

Conflict of Interest. The authors declare that they have no conflict of interest.

\section{References}

Abbott, W. 1925. A method for computing the effectiveness of an insecticide. Journal of Entomology, 18: 265-267.

Baena-Díaz, F., Martínez-M, I., Gil-Pérez, Y., GonzálezTokman, D. 2018. Trans-generational effects of ivermectin exposure in dung beetles. Chemosphere. 202: 637-643.

Blume, R.R., Aga, A. 1975. Onthophagus gazella: 1 mass rearing and laboratory biology. Environmental Entomology, 4: 735-736.

Boleas, S., Alonso, C., Pro, J., Fernández, C., Carbonell, G., Tarazona, J.V. 2005. Toxicity of the antimicrobial oxytetracycline to soil organisms in a multi-speciessoil system (MS · 3) and influence of manure coaddition. Journal of Hazardous Materials, 122: 233-241.

Burger, B.B.V. 2014. The first investigation of the semiochemistry of south African dung beetle species. Neurobiology of Chemical Communication, chaptar no. 3: 57-98.

Chandra, K., Khan, S., Gupta, D. 2012. New records to the species diversity of family Scarabaeidae and Hybosoridae (Coleoptera: Scarabaeoidea) of Jabalpur, Madhya Pradesh (India). Academic Journal of Entomology, 5: 28-36.

Chihiya, J., Gadzirayi, T.C., Mutandwa, E. 2015. Effect of three different treatment levels of deltamethrin on the numbers of dung beetles in dung pats. African Journal of Agricultural Research, 1: 074-077.

Davis, A.L., Scholtz, C.H., Dooley, P.W., Bham, N., Kryger, U. 2004. Scarabaeine dung beetles as indicators of biodiversity, habitat transformation and pest control chemicals in agro-ecosystems. South African Journal of Science, 100: 415-424.

Dormont, L., Raptor, S., McKay, D.B., Lumaret, J.P. 2007. Influence of dung volatiles on the process of resource selection by coprophagous beetles. Chemoecology, 17: 23-30. 
Dormont, L., Epinat, G., Lumaret, J.P. 2004. Trophic preferences mediated by olfactory cues in dung beetles colonizing cattle and horse dung. Environmental Entomology, 33: 370-377.

Floate, K.D. 2006. Endectocide use in cattle and fecal residues: environmental effects in Canada. Canadian Journal of Veterinary Research, 70: 1-10.

Foster, G., Bennett, J., Bateman, M. 2014. Effects of ivermectin residues on dung invertebrate communities in a UK farmland habitat. Insect Conservation and Diversity, 7: 64-72.

Ghazanfar, M., Hussain, M., Abbas, Z., Batool, M. 2017. Diversity and composition of dung beetle fauna in Croplands and Pastures of Jhelum, Punjab, Pakistan. Pakistan Journal of Science, 69: 369374.

Hooper, D., Wolfson, J. 1985. The fluoroquinolones: structures, mechanisms of action and resistance and spectra of activity in vitro. Antimicrobial Agents Chemotherapy, 28: 581-586.

Iwasa, M., Maruo, T., Ueda, M., Yamashita, N. 2007. Adverse effects of ivermectin on the dung beetles, Caccobius jessoensis Harold and rare species, Copris ochus Motschulsky and Copris acutidens Motschulsky (Coleoptera: Scarabaeidae), in Japan. Bulletin of Entomological Research, 97: 619-25.

Iwasa, M., Sugitani, M. 2014. Effects of the veterinary antiparasitic drug eprinomectin on dung beetles (Coleoptera: Scarabaeidae) the non-pest fly Neomyia cornicina and pest fly Haematobia Irritans (Diptera: Muscidae) in Japan. Journal of Applied Entomology, 49: 591-597.

Jacobs, C.T., Scholtz. 2015. A review on the effect of macrocyclic lactones on dung-dwelling insects: toxicity of macrocyclic lactones to dung beetles. Journal of Veterinary Research, 82: 1-8.

Li, Y., Hu, Y., Ai, X., Qui, J., Wang, X. 2015. Acute and sub-acute effects of enrofloxacin on the earthworm species Eisenia fetida in an artificial soil substrate. European Journal of Soil Biology, 66: 19-23.

Lumaret, J. P. 1986. Toxicité de certains helminthicides vis-à-vis des insectes coprophages et conséquences sur la disparition des excréments de la surface du sol. Acta Oecologia, 7: 313-324.

Lumaret, J. P., Errouissi, F., Floate, K., Rombke, J., Wardhaugh, K. 2012. A review of the toxicity and non-target effects of macrocyclic lactones in terrestrial and aquatic environments. Current Pharmaceutical Biotechnology, 13: 1004-1060.

Lumaret, J.P., Errouissi, F., Gautier, Alvinerie, M. 2005. Pour-on formulation of eprinomectin for cattle: fecal elimination profile and effects on the development of the dung-inhabiting Diptera Neomyiacornicina (L.) (Muscidae), Environmental Toxicology Chemistry, 24: 797-801.

Suarez, V.H., Lifschitz, A.L., Sallovitz, J.M., Lanusse, C.E. 2003. Effects of ivermectin and doramectin fecal residues on the invertebrate colonization of cattle dung. Journal of Applied Entomology, 127: 481-488.

Verdú, J.R., Cortez, V., Ortiz, A.J., González-Rodríguez, E., Martinez-Pinna, J., Lumaret, J.P., Sánchez Piñero, F. 2015. Low doses of ivermectin cause sensory and locomotor disorders in dung beetles. Scientific Reports, 5: 13912. 